\title{
Instructions for Irrigating and Watering Plants (Indonesian Version)
}

\author{
Uqbah Iqbal* and Jalan Munshi Abdullah
}

Department of Life Planner, Kuala Lumpur

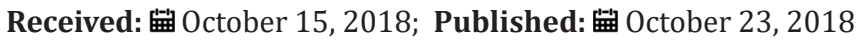

*Corresponding author: Uqbah Iqbal, Department of Life Planner, Suite P4, Level 31, AIA Cap Square Tower, 50100 Golden Triangle, Kuala Lumpur

\section{Opinion}

Written by Ir. Sri Najiyati \& Ir. Danarti, human efforts to fulfill and regulate the need for plants for water, which is often called irrigation, have developed since ancient times. Although at that time the methods and tools used were still traditional and makeshift. At present the business has increased with technology. Various characteristics of plants in relation to water have been studied and sophisticated and modern mechanization tools have also been found, so that irrigation can be carried out appropriately both time and method as well as the amount of water requirements without requiring much labor. The description in this book begins with a description of the properties of water in nature and in relation to plants and the characteristics of each type of plant for water needs. Also contains instructions on ways to provide water for plants both traditional and modern, because according to the authors traditional methods are still relevant while modern methods are feasible to be implemented in Indonesia. Water is one of the factors that is very important for plant life. It is not surprising that its existence is very influential on the types of plants that live somewhere. In areas that have high rainfall, we will find plants that need a lot of water, while in areas with low rainfall we will find plants that are resistant to drought.

The role of water for plant life is water as a nutrient solvent in the soil so that plants can easily take the nutrient through the roots as food and at the same time transport the hope to parts of plants that need it. Water is one of the important components in photosynthesis, namely the process of forming carbohydrates from water and carbon dioxide with the help of sunlight. Almost all plant physiology processes including chemical reactions take place in the presence of water. Inside the water plant functions to maintain the firmness of the plant. If the plant lacks water, the plant will wither and then die. Water as a temperature controller in plants when the sun is hot. When the sun is hot, leaves and other parts of the plant will overheat so that the temperature can rise continuously if there is no one to control it, namely water. Water controls the temperature of the plant by evaporation through the stoma on the leaf surface. Because evaporation requires heat, so the temperature of the plant that was too high became constant again. The benefits of water for plants are very large and their presence around the plants is an absolute requirement for plants to take the water for their lives. But its existence can also be a disaster if the amount is excessive. All plants need water, but their needs vary depending on the type. Rice, for example, requires a lot of water almost during its growth period. Instead the cactus will languish if it lives in an environment that contains lots of water. On this earth there are approximately 1.3-1.4 billion cubic $\mathrm{km}$ of water. But this large amount is not all around the plants we cultivate but most of them are in the sea, in rivers, in lakes, in swamps, in the air as clouds or as groundwater that is not accessible to the roots of plants. For plants to meet their water needs, cultivating human intervention is very necessary. Human intervention to meet the needs of plants for water is called irrigation. According to the method of administration the irrigation system is divided into three, namely watering systems, aboveground irrigation and subsurface irrigation. Watering is a system of giving water by spraying so that the fall of water to the surface of the soil / plant will be in the form of granules that resemble rain. While irrigation is a system of giving water by flowing and flooding above the soil surface or from below the soil surface. In the past, when humans were not familiar with advanced technology, the new irrigation system was carried out simply with a makeshift tool. The water channels that are made are generally not permanent and are easily damaged so that plants that require a lot of water such as rice can generally only be planted in the rainy season or once a year. Irrigation like this is known as non-technical irrigation. At this time when humans have known advanced technology, irrigation and watering systems have evolved along with technological developments. 


\section{(c) \\ This work is licensed under Creative Commons Attribution 4.0 License}

To Submit Your Article Click Here:

Submit Article

DOI: $10.32474 /$ CIACR.2018.05.000204

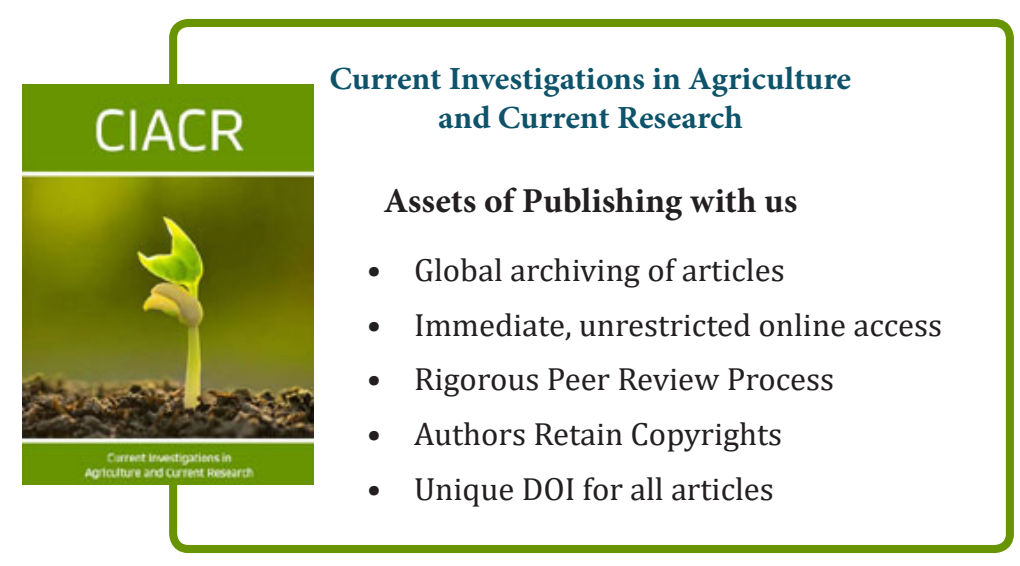

